\section{Meta-heuristic algorithms for solving the sustainable agro-food grain supply chain network design problem}

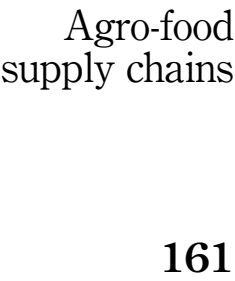

Ashish Dwivedi

Indian Institute of Technology Delhi, New Delhi, India

Ajay Jha

Department of Transportation Management, University of Petroleum and Energy Studies, Dehradun, India

Dhirendra Prajapati Mechanical Engineering, IIITDM Jabalpur, Jabalpur, India

Nenavath Sreenu

Management Studies, MANIT, Bhopal, India, and

Saurabh Pratap

Mechanical Engineering, IIITDM Jabalpur, Jabalpur, India
Received 23 April 2020

Revised 11 July 2020

6 September 2020

Accepted 6 September 2020
30 August 2020

\begin{abstract}
Purpose - Due to unceasing declination in environment, sustainable agro-food supply chains have become a topic of concern to business, government organizations and customers. The purpose of this study is to examine a problem associated with sustainable network design in context of Indian agro-food grain supply chain.

Design/methodology/approach - A mixed integer nonlinear programming (MINLP) model is suggested to apprehend the major complications related with two-echelon food grain supply chain along with sustainability aspects (carbon emissions). Genetic algorithm (GA) and quantum-based genetic algorithm (Q-GA), two metaheuristic algorithms and LINGO 18 (traditional approach) are employed to establish the vehicle allocation and selection of orders set.

Findings - The model minimizes the total transportation cost and carbon emission tax in gathering food grains from farmers to the hubs and later to the selected demand points (warehouses). The simulated data are adopted to test and validate the suggested model. The computational experiments concede that the performance of LINGO is superior than meta-heuristic algorithms (GA and Q-GA) in terms of solution obtained, but there is trade-off with respect to computational time.

Research limitations/implications - In literature, inadequate study has been perceived on defining environmental sustainable issues connected with agro-food supply chain from farmer to final distribution centers. A MINLP model has been formulated as practical scenario for central part of India that captures all the major complexities to make the system more efficient. This study is regulated to agro-food Indian industries.

Originality/value - The suggested network design problem is an innovative approach to design distribution systems from farmers to the hubs and later to the selected warehouses. This study considerably assists the organizations to design their distribution network more efficiently.
\end{abstract}

Keywords Agro-supply chain, Sustainability, Mixed integer nonlinear programming, Meta-heuristics Paper type Research paper

(C) Ashish Dwivedi, Ajay Jha, Dhirendra Prajapati, Nenavath Sreenu and Saurabh Pratap. Published in Modern Supply Chain Research and Applications. Published by Emerald Publishing Limited. This article is published under the Creative Commons Attribution (CC BY 4.0) license. Anyone may reproduce, distribute, translate and create derivative works of this article (for both commercial and non-commercial purposes), subject to full attribution to the original publication and authors. The full terms of this license

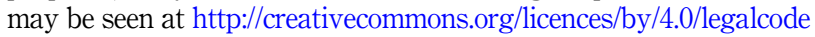


MSCRA

2,3

162

\section{Sets and indices}

$n \quad$ The set of hubs $n \in N$

$m \quad$ The set of farmers $m \in \mathrm{M}$

$i \quad$ The set of warehouses $i \in I$

$v \quad$ Set of vehicles, $v \in V$

$k, l \quad$ Node in suggested model $k \& l \in(M \cup N)$

Parameters

$H Q_{m} \quad$ The harvest amount of quantity proposed to supply from the farmer $m$

Aval $l_{n} \quad$ Availability of food grains at the collection hub $n$

$Q_{i} \quad$ The demanded quantity by warehouse $i$

$d_{k m}^{f, f^{\prime}} \quad$ Distance among farmer $k$ to farmer $m(k \neq m)$

$d_{m n}^{f, c h} \quad$ Distance among farmer $m$ to collection hub $n$

$d_{n i}^{c h, w} \quad$ Distance between collection hub $n$ to warehouse $i$

$c_{1}^{T} \quad$ Transportation cost $(\$ /$ miles) during collection of foods from different farmers

$c_{2}^{T} \quad$ Transportation cost ( $\$$ /miles) from collection hub $n$ to warehouse $i$

$c_{1}^{f c} \quad$ Carbon emission taxation cost $(\$ /$ miles) during collection

$c_{2}^{f c} \quad$ Carbon emission taxation cost (\$/miles) from collection hub $n$ to warehouse $i$

$\alpha_{v}^{f, c h} \quad$ Capacity of the vehicles used for collection

$\alpha_{v}^{c h, w} \quad$ Capacity of the vehicles moving in between collection hub $n$ to warehouse $i$

$\eta_{v}^{c h, w} \quad$ Average mileage of vehicle moving at the speed where economical fuel consumption occurs during shipment from collection hub $n$ to warehouse $i$

$\eta_{v}^{f, c h} \quad$ Average mileage of vehicle moving at the speed where economical fuel consumption occurs during collection

$p_{k l} \quad$ The amount of product shifting from node $k$ to node $l$

LT Lead time

$R S \quad$ Range of speed of vehicle

Decision variables

$S_{\text {niv }} \quad$ Average speed of vehicle $v$ moving from collection hub $n$ to warehouse $i$

$S_{m n v} \quad$ Average speed of vehicle moving from farmer $k$ to hub $n$, and farmer $k$ to farmer $m, k \in M(k \neq M)$

$q_{\text {niv }} \quad$ Quantity moving from collection hub $n$ to warehouse $i$ with assigned vehicle $v$

$q_{m n v} \quad$ Quantity moving from farmer $m$ to hub $n$ with assigned vehicle $v$

$n_{v}^{c h, w} \quad$ Number of vehicles required to shipment from collection hub $n$ to warehouse $i$

$n_{v}^{f, c h} \quad$ Number of vehicles required for collection from different farmer locations

$x_{\text {niv }}^{c h, w}=\left\{\begin{array}{l}1, \text { if vehicle } v^{\prime} \text { assigned for shipment from collection hub }{ }^{\prime} n^{\prime} \text { to warehouse }{ }^{\prime} i^{\prime} \\ 0, \text { otherwise }\end{array}\right.$

$y_{k l v}^{f, f^{\prime}}=\left\{\begin{array}{l}1, \text { if vehicle }{ }^{\prime} v^{\prime} \text { assigned for shipment from any farmer node }{ }^{\prime} k^{\prime} \text { to farmer node }{ }^{\prime} l^{\prime} \\ 0, \text { otherwise }\end{array}\right.$

$y_{k n v}^{f, c h}=\left\{\begin{array}{l}1, \text { if vehicle } v^{\prime} \text { assigned for shipment from any farmer node }{ }^{\prime} k^{\prime} \text { to collection hub }{ }^{\prime} n^{\prime} \\ 0, \text { otherwise }\end{array}\right.$

\section{Introduction}

India is an agricultural nation with majority of its population reliant on agriculture in a direct or indirect manner (Gouda et al., 2018). The food supply chain commits significantly toward sustainable ecosystem of the nation (Allaoui et al., 2018). It coordinates the main factors (such as information related to the farmer hubs, network connectivity across hubs, distribution 
centers, various transport routes, etc.) related with the production and dispersion of agricultural food products. In India, the federal government and the state governments are actively involved in regulating and controlling the production, distribution and processing of food products. Food Corporation of India (FCI), a federal government agency actively participates in purchase and distribution of food grains and other agriculture products. FCI in consultation with the state governments, has established a number of purchase centers (mandis) at various locations to smoothen the purchase of food grains. The role of FCI and other state agencies is to safeguard the interest of farmers such that they are not obligated to sell their products for less than the minimum support price. FCI procures directly from farmers (or through its agents) from the surplus producing states and performs distribution throughout the country via its various warehouses and other state-controlled storage houses (Prakash, 2018). Despite the government interventions, various inefficiencies exist in the Indian food supply chain. The current procurement system via designated markets (mandis) fail to address the entire country uniformly. The farmers are required to travel large distances to reach the adjacent mandi and numerous times they have to wait to get their grain unloaded in the mandis (Mogale et al., 2019). In India, majority of farmers have small and fragmented landholdings which make them vulnerable to weather risks, lesser surplus crop and money-lenders (Dev, 2012). The above problems result in construction of long marketing channels, with multiple intermediaries and ultimately poor farmer bargaining power. These intermediaries have direct influence on cost inflation and information asymmetry in agriculture, specifically for non-Minimum Support Price crops. Due to purchases, traffic, other taxes and service fees imposed on different layers, a perversely long supply chain leads to a sharp increase in the total cost. As a result of such shortcomings in the supply chain, it has been anticipated that the farmers obtain less amount that the consumer pays. Also, there exists a large gap between agriculture-warehousing supply and demand. Prioritizing marketing management and linking farmers directly to consumers is one of the solutions to counter the agricultural pressure confronted by the farmers (Arulananth and Vishwanathan, 2020).

Another important issue in agro-supply chain is the cost of transportation. The medium and large-scale farmers can afford to bear the logistics cost in meeting the market requirements but it is the marginal farmer, who cannot bear the cost. Therefore, the marginal farmers suffer at the hands of the intermediaries. Also, most of the farmer's production is transported through tractors and via not so good village roads, leading to non-efficient mode of transportation. Hence, on the sustainability front the greenhouse gas (GHG) emissions are also a major concern to the policy planners. Indian agro-food industries are striving to deal with the logistics providers, farmers' assembly center and food vendor centers to moderate the carbon emissions generated because of increased fuel consumption during transportation. The present study features few research objectives reflected below:

RO1. To address the concern of the farmers' highlighted above for enhancing the agrosupply chain efficiencies.

RO2. To minimize the costs associated with the movement of food grains.

RO3. To centralize the collection of the farmers' production and transportation issues.

The present study attempts to address the above highlighted concerns related to agro-supply chain efficiencies through integrated logistics planning for upstream food grain purchase. The present study has some contributions to the literature:

(1) A mathematical model is suggested to minimize the costs related with transportation and carbon emissions via centralized planning for the movement of food grains from farms to the purchase hubs and subsequently to the required warehouses in the country. 
MSCRA

2,3

164

(2) The centralization for the collection of farmers' production and transportation can be performed through optimized routes and vehicle planning.

(3) The study will assist organizations to address the sustainability issues (farmers' interests, cost of purchase and carbon emissions) in purchase and optimal transportation of food grains.

The study is drafted in six sections. Section 1 presents an introduction to the study. Section 2 reviews the relevant literature related to agro-food supply chain and carbon emissions. In Section 3, problem description and problem statement is discussed. In Section 4, the different solution approaches adopted for the study are highlighted. Section 5 , highlights the results and discussions. Finally, conclusion, limitations and future research directions are presented in Section 6.

\section{Literature review}

The agro-food segment contributes a potential part toward the Indian economy. Still, scant studies are evident in the literature associated to agro-food supply chains. Currently, sustainable supply chain (SSC) requires that they meet the three aspects of sustainability (Dwivedi et al., 2019; Moktadir et al., 2019, 2020). In this study, environmental aspect of sustainability is considered in the agriculture domain. The literature review segment is segregated into studies based on agro-food supply chain and carbon emission on supply chain network.

\subsection{Agro-food supply chain network design}

Galal and El-Kilany (2016) studied the results of varying order quantity in agro-supply chain. In the study, a simulation model was established to involve stochastic demand and time. Further, Orjuela-Castro et al. (2017) suggested a mathematical model for solving a problem related to supply chain of perishable foods. A mixed integer linear programming (MILP) approach was adopted for localization of collection hubs based on multi-echelon-multi-products transport system. Similarly, Miranda-Ackerman et al. (2017) designed a framework considering the case of processed food industry. A mixed approach of multi-objective optimization and multiplecriteria decision-making (MCDM) was embraced for solving the three-echelon green supply chain model. A literature survey was performed to study agent-based modeling in context of agro-supply chains (Utomo et al., 2018). An analysis of different models and modeling approaches were presented in the study. Further, Sazvar et al. (2018) framed a study examining the SSC with deteriorating product for an agro-food industry. A mathematical model was produced for the problem and was solved using an augmented $\varepsilon$-constraint approach. Similarly, Esteso et al. (2018) suggested a model for designing agro-food supply chains. In the study, development and analysis of models constructed on mathematical programming was performed for network design. Mangla et al. (2018) identified and investigated the potential enablers for successful sustainable plans in the domain of agro-food supply chains. A mixed approach of ISM-DEMATEL was utilized for analyzing the enablers. Also, Jonkman et al. (2019) constructed a network design problem related to agro-food industry examining the harvesting decisions. Further, the model was practiced considering the case of sugar beet processing chain. A literature review was performed to identify the indicators for evaluating sustainability for real cases of supply chain network design (Moreno et al., 2019). Chowdhury et al. (2019a, b) performed a study to advance a SSC assessment model. The study adopted a combined approach to develop the model. Supply chain risk assessment was performed in context of developing countries (Chowdhury et al., 2019a, b; Karuppiah et al., 2020). Hu et al. (2019) studied four echelon agro-food supply chain with multiple strategies. In the study, a hybrid 
coordination mechanism was established for quality control of agro-food supply chain. Further, Ali et al. (2019) presented a framework for risk evaluation in food supply chains. Similarly, Meena et al. (2019) studied an Indian agro-food supply chain problem and identified the important factors affecting the agro-food supply chain using Fuzzy analytic hierarchy process (AHP) method. Chen et al. (2020) designed a knowledge network examining lean supply chain decisions with respect to agro-food industry. An AHP technique was adopted for attaining different lean performance objectives in the study. Kamble et al. (2020) identified enablers related to block chain technology in context of agro-supply chain. The identified enablers were further analyzed using combined ISM-DEMATEL approach. highlighted the issues to adoption of circular economy in product recovery systems (Dwivedi et al., 2020; Dwivedi and Madaan, 2020). Kumar et al. (2020) highlighted the challenges to electric vehicle adoption adopting sharing economy. Further, Chowdhury and Paul (2020) presented a literature review in context of corporate sustainability adopting MCDM methods.

\subsection{Carbon emission}

SSC refers to comprehensive assessment of supply chain operations and logistics that influence the economic, social and environmental aspect of supply chain factors. In domain of, sustainable agro-supply chain it can be observed as identifying the surplus food producing region, developing proper purchase and logistic systems, ensuring good returns to the stakeholders, ensuring good product to the customers and reducing the carbon footprint. World Health Organization (WHO) recognized global transport energy growth (mainly land transport) as the major contributor of carbon di-oxide $\left(\mathrm{CO}_{2}\right)$ and black carbon emissions produced mainly by diesel vehicles. $\mathrm{CO}_{2}$ has been in the atmosphere for more than a period, with continuing warming effects (IPCC, 2014). India as a signatory to the Paris Agreement on Climate (2016) sworn to cut 33-35\% emissions related with every unit of economic output by 2030. Researchers gave ample attention to address the carbon footprint in the sustainability of supply chains. However, most of the studies gave preference to modeling approach when compared to the case studies.

A large amount of carbon associated concerns such as carbon emissions trading put stress on organizations to record their emissions and report them across their supply chains. In reply, carbon identification and measurement specify a method for handling and accessing risks and prospects associated with climate business (Lash and Wellington, 2007). Pratap et al. (2019) described an multi-objective model of shipping network design and analyzed the influence of carbon emission tax on shipping of cargo goods. Sundarakani et al. (2008) performed a study related to measurement of carbon footprints across the supply chains. Wittneben and Liyar (2009) while examining automobile supply chain, highlighted the importance of quantifying direct GHG and critical role of suppliers and site-operations. Sundarakani et al. (2010) studied the carbon footprint through analytical model adopting the Lagrangian and Eulerian methods. The findings reflect that carbon emissions across different stages in the supply chain can pose a major risk that requires consideration during the supply chain design phase. In context of agro-supply chain, Wakeland et al. (2012) specified an outline of success factors associated with transportation and accommodation of food from production to the retailer. The study implemented carbon review approaches to recognize opportunities for reduction in GHG emissions. Ingrao et al. (2015) performed a study for the environmental evaluation of agro-biogas supply chain with special reference point as carbon footprint analyses in the operations. Accorsi et al. (2016) performed a study related to design carbon balanced and cost effective agro-supply chains. A land network problem was considered in the agro-food network design and solved using linear programming model. Mogale et al. (2019) developed a decision support model considering network of purchase centers, central warehouses and fair-value stores for sustainable food 
MSCRA

2,3 grain supply chain. The study adopted multi-objective algorithms to solve the problem and performed sensitivity analysis using multiple scenarios. The model investigates to minimize cost and $\mathrm{CO}_{2}$ emissions. A model for intermodal freight transportation was proposed in context of emerging economies (Shardeo et al., 2020a, b).

\subsection{Motivation for the study}

In the previous section, literature review suggests a lot of studies related to SSC context, here the studies in modeling carbon footprint aspect of sustainability has been piecemeal. The present study attempts to model the carbon footprint by taking into account the type of transportation route and the vehicle speed, which are important determinants of the carbon emissions from a vehicle. An attempt has been made to solve the facility allocation model while minimizing the transportation cost and the carbon emissions. The complex nonlinear integer mathematical model motivates us to explore three different solution methodologies to come up with best solution.

\section{Problem description}

In the agricultural sector, demand and procurement is highly unstructured. For a particular season, varying need and purchasing of the food products via purchase hubs comprises of various costs. The disaggregated collection process where the farmer comes to the hubs (mandis) to sell his products results in enhancement of the the total costs acquired in the supply chains. The farmers travel to the nearest market hub results in high transportation costs, carbon emissions and reduced profitability for the farmers. To counter this situation, a centralized assembly of the food products from the farmers' location to the hub is provided. This results in reduced role of intermediaries and enhanced profitability of the individual farmers. Due to the government policy, the logistic service provider has to pay carbon emission tax. This carbon emission tax is directly proportional to the fuel consumption of vehicles (which is the function of the vehicle/truck speed and load). A mathematical model is framed with an objective of minimizing the transportation and carbon tax cost and satisfying different constraints linked with food grain supply chain. The suggested model is designed for single period and employs numerous vehicles with constant capacity. Further, the model reflects the maximum cost associated with the distance covered by the vehicle in terms of transport and carbon emission tax.

\subsection{Problem statement}

In the present study, a MINLP model is formulated for a two-echelon vehicle routing problem. The model is expected to have a single time demand, one product, multihubs, multiwarehouse and multiple vehicles with a fixed transportation cost and a fixed travel capacity at a maximum limited distance. The total cost includes the transportation cost spent across farmers to a hub, anthropogenic gas emission cost and vehicle routing cost. To reduce the total cost, it is necessary to identify the farmers' allocation to hubs. The fuel emission rate is directly related to the fuel consumption rate given by the carbon emission index parameters (Bektas and Laporte, 2011).

In the study, a set of geologically dispersed farmers are considered that generate single type food grain products for an inbound food product collection system as shown in (Figure 1) below. A number of vehicles are sent to accumulate the product from the hubs. The vehicles are allocated from the hub to the nearest villages, based on the availability at the village and the demand at the warehouses. Numerous restrictions are imposed for the capacity of vehicle, supply at villages, demand at hub and warehouses. 


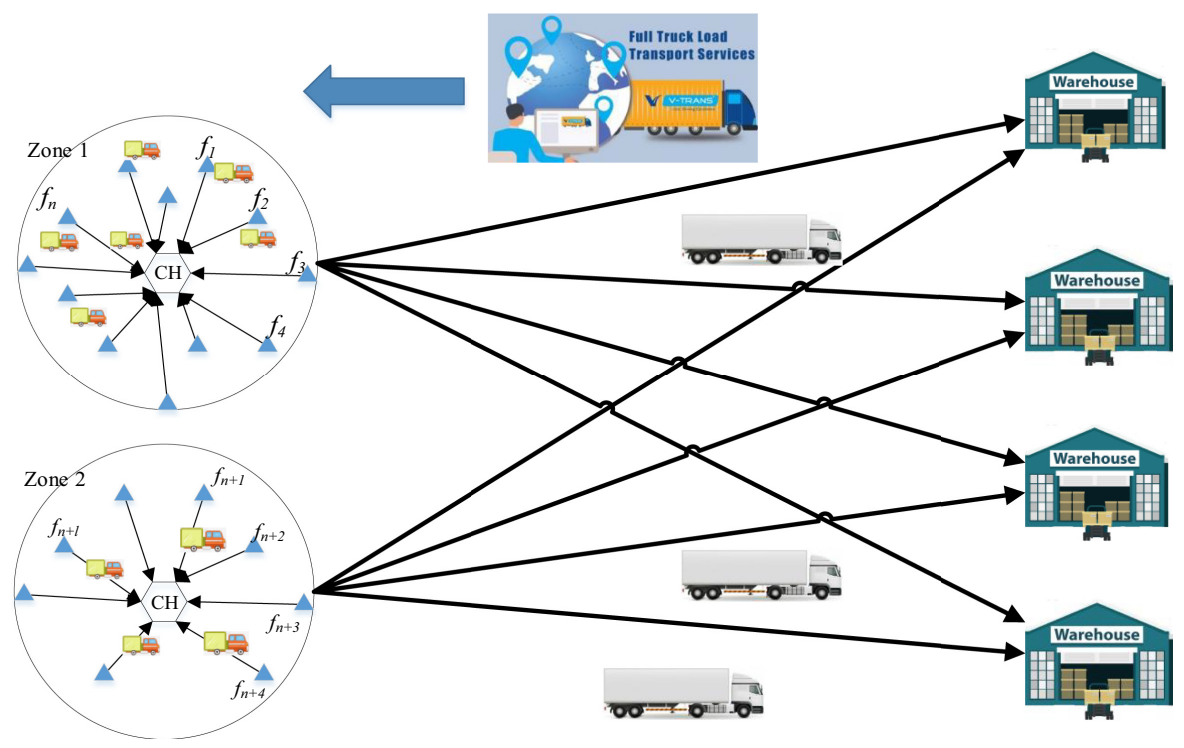

The purpose of the suggested model is to reduce the fixed and variable transportation costs, and the carbon emission costs. Further, the formulated model is expected to improve the farmers' profitability and develop sustainable food grain supply process. The proposed model addresses the below mentioned questions:

(1) The amount of quantity dispatched from farmers to the hub on demand from the availability of farmers' products and the hub.

(2) The vehicle route assigned for each hub.

(3) The total number of vehicles required.

Objective function

$$
\begin{aligned}
\min \left\{\sum_{n \in N} \sum_{i \in I} \sum_{v \in V} c_{2}^{T} d_{n i}^{c h, w} n_{v}^{c h, w} x_{n i v}^{c h, w}+\sum_{n \in N} \sum_{i \in I} \sum_{v \in V} c_{2}^{c t} \frac{d_{n i}^{c h, w}}{\eta_{v}^{c h, w}} n_{v}^{c h, w} x_{n i v}^{c h, w}\right\} \\
+\left\{\begin{array}{l}
c_{1}^{T}\left(\sum_{k \in M(k \neq M)} \sum_{n \in N} \sum_{v \in V} d_{k n}^{f, c h} n_{v}^{f, c h} y_{k n v}^{f, c h}+\sum_{k \in M(k \neq M) l \in M(k \neq M)} \sum_{v \in V} d_{k l}^{f, f^{\prime}} y_{k l}^{f, f^{\prime}}\right) \\
+c_{1}^{c t}\left(\sum_{m \in M} \sum_{n \in N} \sum_{v \in V} \frac{d_{m n}^{f, c h}}{\eta_{v}^{f, c h}} n_{v}^{f, c h} y_{m m v}^{f, c h}+\sum_{k \in M(k \neq M) l \in M(k \neq M)} \sum_{v \in V} \frac{d_{k m}^{f, f^{\prime}}}{\eta_{v}^{f, c h}} y_{k l v}^{f, f^{\prime}}\right)
\end{array}\right\}
\end{aligned}
$$

subjected to

$$
\begin{gathered}
q_{n i v} x_{n i v}^{c h, w}=Q_{i}, \forall n \in N, i \in I, v \in V \\
q_{n i v} x_{n i v}^{c h, w} \leq A v a l_{n}, \forall n \in N, i \in I, \forall v \in V s
\end{gathered}
$$


MSCRA

2,3

168

$$
\begin{aligned}
& q_{m m v}\left(y_{m m v}^{f, c h}+y_{k l v}^{f, f^{\prime}}\right) \leq H Q_{m}, \forall m \in M, n \in N, \forall v \in V, k \in(M \cup N), l \in(M \cup N) \\
& \sum_{n \in N} \sum_{v \in V} x_{n i v}^{c h, w}=1, \forall i \in I \\
& \sum_{k \in(M \cup N)} \sum_{v \in V} y_{k l v}^{f, f^{\prime}}=1, \forall l \in L \\
& \sum_{k \in(M \cup N)} \sum_{v \in V} y_{l k v}^{f f^{\prime}}=1, \forall l \in L \\
& y_{k l v}^{f, f^{\prime}}=\left\{\begin{array}{l}
1, \text { if } \sum_{m \in M} q_{m n v} \leq \alpha_{v}^{f, c h} \\
0, \text { otherwise }
\end{array} \forall k \in K, l \in L, n \in N, v \in V\right. \\
& \sum_{n \in N} \sum_{v \in V} y_{m m v}^{f, c h}=1, \forall m \in M \\
& \sum_{k \in(M \cup N)} y_{k j v}^{f f^{\prime}}=\sum_{l \in(M \cup N)} y_{j l}^{f, f^{\prime}}, \forall, v \in V, j \& j \in(K \cup L) \\
& \sum_{m \in M} q_{m n v} x_{m m v}^{f, c h} \leq \sum_{v \in V} \alpha_{v}^{f, c h}, \forall n \in N \\
& q_{n i v} x_{n i v}^{c h, w} \leq \sum_{v \in V} \alpha_{v}^{c h, w}, \forall n \in N, i \in I \\
& p_{n j}=p_{k l}-p_{n}, \text { if } n \in M, \forall k \in K, j \in(M \cup N) \\
& \sum_{k \in(M \cup N) l \in(M \cup N)} \sum_{v \in V} y_{k l v}^{f, f^{\prime}}+\sum_{k \in(M \cup N)} \sum_{n \in N} \sum_{v \in V} n_{v}^{f, c h} y_{k n v}^{f, c h}+\sum_{n \in N} \sum_{i \in I} \sum_{v \in V} n_{v}^{c h, w} y_{n i v}^{c h, w} \leq G \\
& n_{v}^{c h, w}=\frac{\sum_{n \in N} \sum_{i \in I} q_{n i v} x_{n i v}^{c h, f}}{\alpha_{v}^{c h, f}}, \forall v \in V \\
& n_{v}^{c h, f}=\frac{\sum_{n \in N} \sum_{i \in I} q_{n i v} x_{n i v}^{c h, f}}{\alpha_{v}^{c h, f}}, \forall v \in V \\
& \frac{d_{m i v}^{c h, w}}{S_{n i v}} x_{n i v}^{c h, w}+\frac{d_{m m v}^{f, c h}}{S_{m n v}} y_{k n v}^{f, c h}+\frac{d_{k l v}^{f, f^{\prime}}}{S_{m n v}} y_{k l v}^{f f^{\prime}} \leq L T, \forall n \in N, \forall m \in M, k \in M, l \in M,(k, l \neq M), \\
& v \in V \\
& S_{m n v}, S_{n i v} \in R S, \forall n \in N, \forall m \in M, k \in M, l \in M,(k, l \neq M), v \in V \\
& x_{n i v}^{c h, w}, y_{m n v}^{f, c h}, y_{k l v}^{f, f^{\prime}}=\{0,1\}, \forall n \in N, \forall m \in M, k \in M, l \in M,(k, l \neq M), v \in V
\end{aligned}
$$

In the objective function (Eqn 1), first part computes the total transportation cost and taxation costs associated with carbon emission for shipment of quantity from collection hub to warehouse. The other part computes the total transportation cost and carbon emission 
taxation cost associated with carbon emissions for collection of food items from different farmer places. The constraint (2), is assigned to ensure that the amount of product movement must be greater than or equal to the demand form the warehouse. The purpose of constraint (3), is to assure that the quantity of products shifting from farmers to the hub must be less or equal to the availability at the collection hub. Constraint (4) is introduced to limit the amount of product movement from farmer to the collection hub. This limit should be less than or equal to the available amount of product with the farmers. Constraint (5) is suggested to safeguard that a single collection hub is assigned to a single warehouse. The constraint (6), signifies the arrival of vehicle at any node $l$ from any node $k$ occurs once. Constraint (7), signifies the departure of vehicle from any node $l$ to any node $k$ occurs once. Constraint (8), reflects that if a vehicle reaches to gather the food product and leaves the hub in the practice of gathering product from the farmers. Constraint (9), ensures the maximum capability of the vehicle is greater than the amount provided by the farmers. Constraint (10), is the maximum load transferred in between the node $k$ and node $l$. The constraint (11) is to constrain the total quantity assigned for collection through assigned vehicle must be less or equal to the total available capacity of the assigned vehicles. Constraint (12) is reflected to constrain the total quantity assigned for shipment from collection hub to the warehouse must be less or equal to total available capacity of assigned vehicles. Constraint (13) reflects the maximum weight delivered in between the node $k$ and node $l$ and is represented by means of conservation flow. Constraint (14) confirms that the number of vehicles necessary for routing must be below the available number of vehicles (G). Eqns (15) and (16), compute the number of vehicles essential for shipment from collection hub to the warehouse and for collection of food items from different farmers respectively. Constraint (17), ensures that the lead time should be less than or equal to the total traveling time, which mainly depends on the speed of the vehicle and this speed promotes the carbon emission. Constraint (18), represents the vehicle speed that lies within the specified range of speed which the green economical fuel consumption can meet. Constraint (19), is the binary decision variables constraints.

\section{Solution approach}

\subsection{Approach 1: LINGO optimization tool}

To obtain the solution for the produced MINLP model, LINGO 18 traditional optimization tool with computational machine configuration; 64-bit, Intel core i-7, 8 GB RAM is adopted. LINGO is a proficient for resolving different forms of programming methods such as linear and nonlinear programming, mixed integer programming, quadratic programming, etc. (Prajapati et al., 2020).

\subsection{Approach 2: Genetic algorithm (GA)}

Genetic algorithm (GA) is a stochastic approach and motivated by the Darwin theory of evolution. Holland 1975 studied an adaptive artificial system and used the genetic operator's crossover and reformation of new chromosomes, mutation of the parent and new chromosome and finally evaluates the fitness function. (Pratap et al., 2015; Prajapati et al., 2019) used GA in the scheduling problem to reduce the operational delay.

The generated random solution form chromosomes, the best feasible chromosome have to be selected and proceed for the next operator, i.e. crossover. In one-point crossover operations, the strings have to be selected and swapped with the parents' chromosomes. The feasibility of child chromosomes to be checked and then proceed for the next operator, i.e. mutation. The mutation operator mutates between the strings of chromosomes to improve the solution within the feasible solution space. Finally, fitness function is employed to determine the solution on the basis of selected chromosome. 
MSCRA

2,3

4.3 Approach 3: quantum-based genetic algorithm (Q-GA)

The quantum-based genetic algorithm is encouraged by the quantum computing. The random solution of chromosomes with certain populations are generated as similar to GA. The best population has to be selected among the generated feasible chromosomes. The crossover reforms and generate child chromosome and the concept of quantum entanglement and intercedes updates the solution (Prakash and Vidyarthi, 2013; Niu et al, 2010; Xiao et al, 2010). The process are as follows:

A $t$ bit solution in $n$ bit string can be defined as mentioned in Eqn (20) below:

$$
\left[\begin{array}{lll}
\gamma_{1}(t) \gamma_{2}(t) \gamma_{3}(t) & \ldots & \gamma_{m}(t) \\
\theta_{1}(t) \theta_{2}(t) \theta_{3}(t) & \ldots & \theta_{m}(t)
\end{array}\right]
$$

where $\left|\gamma_{i}\right|^{2}+\left|\theta_{i}\right|^{2}=1, \quad i=1,2,3 \ldots n$

The random initial population is generated as mentioned in Eqn (21) below:

$$
p_{t}(m)=\left[p_{1}(m), p_{2}(m), p_{3}(m) \ldots P_{t}(m)\right]
$$

where, $p_{t}(m)$ is defined as mentioned in Eqn (22) below:

$$
p_{t}(m)=\left[\begin{array}{ccccc}
\gamma_{1}(t) & \gamma_{2}(t) & \gamma_{3}(t) & \ldots & \gamma_{m}(t) \\
\theta_{1}(t) & \theta_{2}(t) & \theta_{3}(t) & \ldots & \theta_{m}(t)
\end{array}\right]
$$

The solutions are updated by adopting quantum rotation operators. $U(\Delta \phi)$ for chromosomes up-to 2 lengths is described as mentioned in Eqn (23) below:

$$
U(\Delta \varphi)=\left[\begin{array}{cc}
\cos (\Delta \phi) & -\sin (\Delta \phi) \\
\sin (\Delta \phi) & \cos (\Delta \phi)
\end{array}\right]
$$

$\Delta \phi$ is the magnitude and sign denoting the angle and direction of rotation. The value of $\Delta \phi$ is to influence the value of convergence and algorithm efficiency. The chromosome's phase is updated for each $t$ bit by $\Delta \phi$ in the direction of global optimal solution. The phase relationship between these $t$ bits, rotated population can be evaluated as mentioned in Eqn (24) below:

$$
\left[\begin{array}{l}
\gamma_{1}(t+1) \\
\theta_{1}(t+1)
\end{array}\right]=U(\Delta \phi)\left[\begin{array}{l}
\gamma_{1}(t) \\
\theta_{1}(t)
\end{array}\right]
$$

The quantum-based mutation operators are used to improve the local search optimal solution and reduce the probability of adolescent convergence. The random number is spawned between the range $[0,1]$ in respective generation. If $(\mathrm{pm})$ is mutation probability and is greater than generated random number, then chromosome can be selected randomly and location of the quality parameters will be exchanged.

Let us assume the random chromosome number is $\left[\gamma_{1}(t) \theta_{1}(t)\right]^{T}$, then mutation will be converted as mentioned in Eqn (25) below:

$$
\left[\begin{array}{l}
\gamma_{1}(t)^{\prime} \\
\theta_{1}(t)^{\prime}
\end{array}\right]=\left[\begin{array}{l}
\theta_{1}(t) \\
\gamma_{1}(t)
\end{array}\right]
$$

The pseudo-code for (Q-GA) approach is reflected below in the Appendix section. The steps of all the associated operators for updating the solutions and the fitness function are reflected below in (Table A1).

\section{Results and discussion}

In this study, a real-life problem has been considered associated with central part of India. The simulated dataset has been used to validate the model. Total 10 case instances have been 
generated from small to large complex scenario (by increasing the number of source and destination points). The code has been run on LINGO and MATLAB software on I7 processor and 8 GB RAM, 1 TB ROM in windows 10 platform.

\subsection{Input data}

To obtain the maximum possible results, the model is established in the LINGO optimization tool. To validate the model, 10 farmer nodes and 2 food hubs are inspected in the first case instance. The data for the supply of food from farmer to hub are presented below in (Table 1):

The distance matrix from the farmer to farmer and farmer to hub nodes are presented in the (Table 2) below:

The obtained values associated with different parameters are presented in (Table 3) below:

\subsection{Output results}

In the present study, LINGO optimization solver and meta-heuristic approach (GA and Q-GA) are adopted. The model has been tested on ten different instances and scenarios. The convergence graph for first and fifth instances of GA and Q-GA are shown in (Figure 2) below:

The computational experiments for 10 different instances (cases) and the associated objective function value (total cost in US\$) along with the computational time for all the instances is presented in (Table 4) below. An increase in the number of nodes from first instance to the 10

\begin{tabular}{lcccccccccccc}
\hline Farmers & $n 1$ & $n 2$ & $m 1$ & $m 2$ & $m 3$ & $m 4$ & $m 5$ & $m 6$ & $m 7$ & $m 8$ & $m 9$ & $m 10$ \\
\hline Quantity & 0 & 0 & 12 & 10 & 6 & 5 & 9 & 6 & 6 & 6 & 6 & 4
\end{tabular}

Table 1

The supply of food products from farmers

\begin{tabular}{lccccccccccccc}
\hline & $m 1$ & $m 2$ & $m 3$ & $m 4$ & $m 5$ & $m 6$ & $m 7$ & $m 8$ & $m 9$ & $m 10$ & $n 1$ & $n 2$ \\
\hline$m 1$ & 0 & 26.15 & 9.51 & 20.52 & 28.04 & 24.8 & 8.99 & 7.06 & 22.63 & 19.79 & 12.79 & 13.86 & \\
$m 2$ & 26.15 & 0 & 14.37 & 15 & 13.61 & 9.48 & 18.2 & 26.2 & 23 & 5.36 & 15.53 & 16.34 & \\
$m 3$ & 9.51 & 14.37 & 0 & 17.2 & 25.53 & 19.46 & 5.66 & 11.75 & 23.53 & 14.73 & 11.25 & 12.55 \\
$m 4$ & 20.52 & 15 & 17.2 & 0 & 16.82 & 9.07 & 11.7 & 22.76 & 9.29 & 12.75 & 27.43 & 28.24 \\
$m 5$ & 28.04 & 13.61 & 25.53 & 16.82 & 0 & 7.76 & 20.12 & 28.14 & 21.27 & 8.24 & 23.89 & 24.89 \\
$m 6$ & 24.8 & 9.48 & 19.46 & 9.07 & 7.76 & 0 & 16.88 & 24.9 & 13.52 & 5.72 & 20.62 & 21.43 \\
$m 7$ & 8.99 & 18.2 & 5.66 & 11.7 & 20.12 & 16.88 & 0 & 11.23 & 19.2 & 12.12 & 14.71 & 18.2 & \\
$m 8$ & 7.06 & 26.2 & 11.75 & 22.76 & 28.14 & 24.9 & 11.23 & 0 & 24.88 & 20.14 & 16.44 & 18.91 \\
$m 9$ & 22.63 & 23 & 23.53 & 9.29 & 21.27 & 13.52 & 19.2 & 24.88 & 0 & 19.23 & 34.13 & 34.94 & Distance from farmer \\
$m 10$ & 19.79 & 5.36 & 14.73 & 12.75 & 8.24 & 5.72 & 12.12 & 20.14 & 19.23 & 0 & 15.89 & 16.7 & to farmer $\left(d_{k m}^{f, f}\right)$ and \\
$n 1$ & 12.79 & 15.53 & 11.25 & 27.43 & 23.89 & 20.62 & 14.71 & 16.44 & 34.13 & 15.89 & 0 & 10 & farmer to hub $\left(d_{m n}^{f, h}\right)$ \\
$n 2$ & 13.86 & 16.34 & 12.55 & 28.24 & 24.89 & 21.43 & 18.2 & 18.91 & 34.94 & 16.7 & 10 & 0 & \\
\hline
\end{tabular}

\begin{tabular}{lccc}
\hline Parameters & Values & Parameters & Values \\
\hline$c_{1}^{f c}$ & $3(\$ / \mathrm{hrs})$. & $c_{1}^{T}$ & $10(\$ /$ miles $)$ \\
$c_{2}^{f c}$ & $1(\$ / \mathrm{hrs})$. & $c_{2}^{T}$ & $15(\$ /$ miles $)$ \\
$Q_{1}$ & 20 & $L T_{1}$ & $4 \mathrm{~h}$ \\
$Q_{2}$ & 20 & $L T_{2}$ & $4 \mathrm{~h}$ \\
$c_{1}^{T}$ & $10(\$ /$ miles $)$ & & \\
$c_{2}^{T}$ & $15(\$ /$ miles $)$ & &
\end{tabular}

Table 3.

The obtained value for different parameters 
MSCRA

2,3

172

Figure 2.

Convergence graphs for GA and Q-GA (Case Instance I and V)
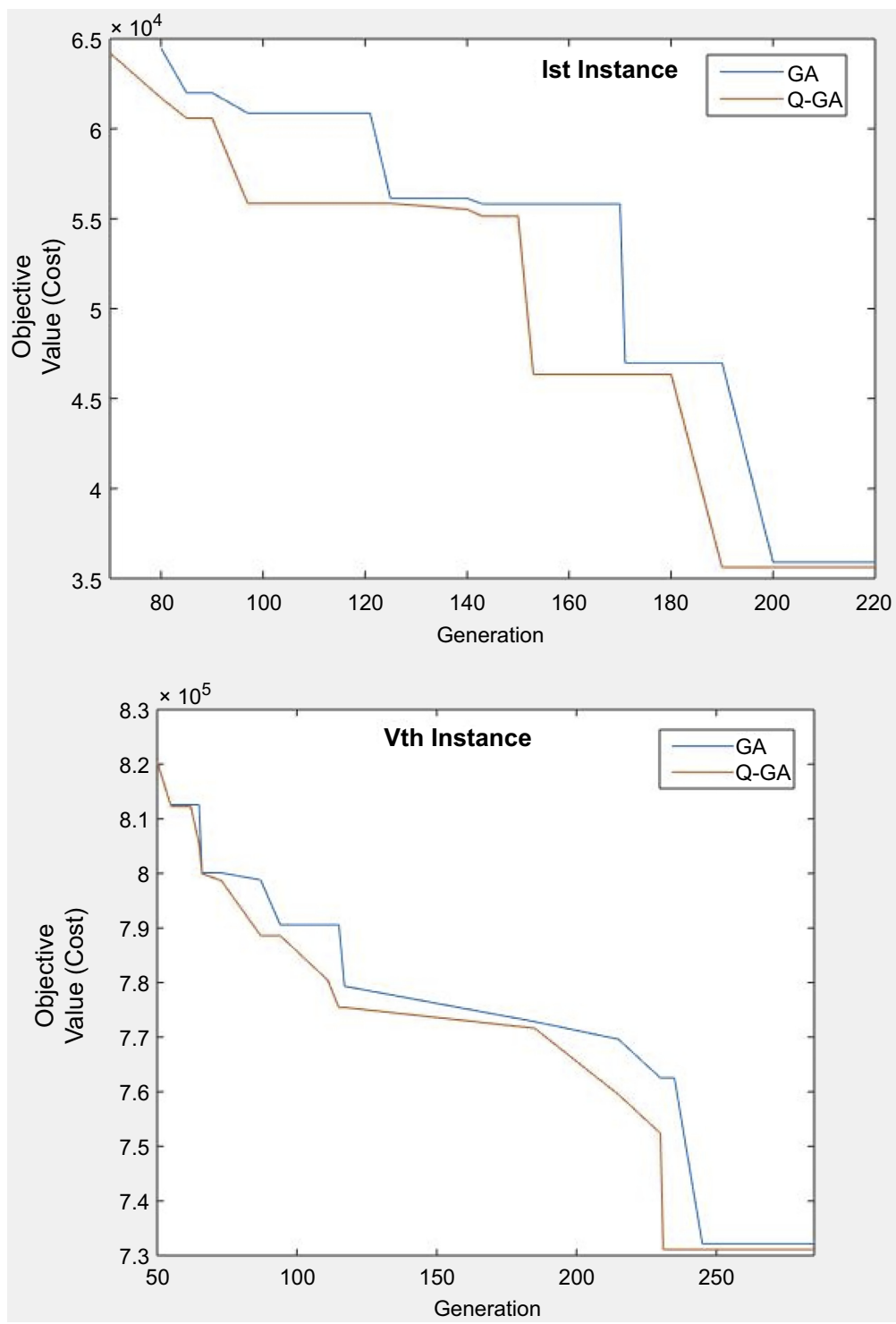

different instances is evident. Further, the total number of increased variables and constraints increases the complexity to solve the model. The LINGO performs better than the proposed metaheuristic approaches in minimizing the total cost, but with relatively longer time (Table 4). The two meta-heuristics have been used to determine the near optimal total cost and discovered that Q-GA performs better than GA, simultaneously in the term of computational time.

\section{Conclusion, limitations and future research directions}

In the present study, a SSC network problem for an Indian agro-food is proposed. A MINLP model is presented to consider all the major complex constraints that influence the flow of agro- 


\begin{tabular}{|c|c|c|c|c|c|c|c|c|}
\hline \multirow[b]{2}{*}{ S. No } & \multirow[b]{2}{*}{$\begin{array}{l}\text { Cases } \\
(\mathrm{m}-\mathrm{n})\end{array}$} & \multicolumn{2}{|c|}{ LINGO } & \multicolumn{2}{|c|}{ GA } & \multicolumn{2}{|c|}{ Q-GA } & \multirow{2}{*}{$\begin{array}{r}\text { Agro-food } \\
\text { supply chains }\end{array}$} \\
\hline & & $\begin{array}{l}\text { Total cost } \\
\text { (US\$) }\end{array}$ & $\begin{array}{c}\text { Computation } \\
\text { time (s) }\end{array}$ & $\begin{array}{c}\text { Total cost } \\
\text { (US\$) }\end{array}$ & $\begin{array}{l}\text { Computation } \\
\text { time (s) }\end{array}$ & $\begin{array}{l}\text { Total cost } \\
\text { (US\$) }\end{array}$ & $\begin{array}{c}\text { Computation } \\
\text { time }(\mathrm{s})\end{array}$ & \\
\hline 1 & $(10-2)$ & 35847.11 & 5.64 & 35901.01 & 4.18 & 35621.21 & 3.24 & \\
\hline 2 & $(12-3)$ & 53284.61 & 22.41 & 54364.64 & 21.24 & 53225.31 & 20.35 & \\
\hline 3 & $(15-2)$ & 63057.85 & 48.67 & 64875.85 & 35.24 & 64518.94 & 31.57 & \\
\hline 4 & $(15-3)$ & 68914.52 & 71.38 & 69874.44 & 41.08 & 69755.60 & 38.39 & 173 \\
\hline 5 & (15-5) & 726541.30 & 102.54 & 732152.21 & 64.23 & 731091.58 & 60.47 & \\
\hline 6 & $(18-3)$ & 915648.18 & 181.04 & 925483.56 & 98.64 & 924894.25 & 95.39 & \\
\hline 7 & $(20-3)$ & 998756.64 & 268.97 & 1024981.08 & 119.34 & 1019877.84 & 110.21 & $\mathrm{Tab}$ \\
\hline 8 & $(20-5)$ & - & - & 1146984.65 & 247.98 & 1132654.94 & 239.10 & Computational \\
\hline 9 & $(25-4)$ & - & - & 1320354.52 & 323.56 & 1319865.48 & 307.64 & ments for 10 case \\
\hline 10 & $(25-6)$ & - & - & 1483601.31 & 397.18 & 1461987.28 & 378.34 & instances \\
\hline
\end{tabular}

food products from source to final destination points. In this model, the significance of the decline in transportation costs and carbon emission tax for a complex food supply chain was established. The proposed mathematical model is formulated to accomplish maximum throughput efficiency during transportation of agro-food products and justifying the financial benefits to the farmers. The objective function and constraints were developed and the data sets adopted were put to test for attaining the effectiveness of the model using LINGO and metaheuristic approaches (GA and Q-GA). The data sets were acquired from the central part of India (FCI data) for obtaining better insights from the actual problem. Further, the suggested model was tested with LINGO, and the results reveal that LINGO performs better than the metaheuristic approaches (GA and Q-GA) in catering to the transportation, aggregation and collection of food grains. The effectiveness of this study is to assist the food grain aggregator in better addressing the upstream food grain supply chain and also contributes theoretically by establishing better performance of LINGO in addressing the MINLP.

The present study reflects some directions for future research. Suggested algorithms can be paralleled with different meta-heuristic techniques such as simulated annealing, ant colony optimization, particle swarm optimization, etc. Recent studies have reflected that hybrid meta-heuristics might perform better than individual meta-heuristics for resolving nonlinear models (Diabat, 2014). Hybridization of the meta-heuristics methods may provide novel insights in the context of agro-supply chain network design. Simulation-based optimization can be performed rather than mathematical programming techniques, which may lead to motivating results.

\section{References}

Accorsi, R., Cholette, S., Manzini, R., Pini, C. and Penazzi, S. (2016), "The land-network problem: ecosystem carbon balance in planning sustainable agro-food supply chains", Journal of Cleaner Production, Vol. 112, pp. 158-171.

Ali, S.M., Moktadir, M.A., Kabir, G., Chakma, J., Rumi, M.J.U. and Islam, M.T. (2019), "Framework for evaluating risks in food supply chain: implications in food wastage reduction”, Journal of Cleaner Production, Vol. 228, pp. 786-800.

Allaoui, H., Guo, Y., Choudhary, A. and Bloemhof, J. (2018), "Sustainable agro-food supply chain design using two-stage hybrid multi-objective decision-making approach", Computers and Operations Research, Vol. 89, pp. 369-384.

Arulananth, M.P. and Viswanathan, M. (2020), "Doubling farmer's income by 2022-role of nationalized banks in its achievement", Purakala with ISSN 0971-2143 is an UGC CARE Journal, Vol. 31 No. 14, pp. 309-323.

Bektas, T. and Laporte, G. (2011), “The pollution-routing problem”, Transportation Research Part B, Vol. 45, pp. 1232-1250. 
MSCRA

2,3

Chen, H., Liu, S. and Oderanti, F. (2020), "A knowledge network and mobilisation framework for lean supply chain decisions in agri-food industry", Supply Chain and Logistics Management: Concepts, Methodologies, Tools, and Applications, IGI Global, pp. 369-381.

Chowdhury, P. and Paul, S.K. (2020), "Applications of MCDM methods in research on corporate sustainability: a systematic literature review", Management of Environmental Quality, Vol. 31 No. 2, pp. 385-405, doi: 10.1108/MEQ-12-2019-0284.

Chowdhury, B., Lin, L., Dhar, B.R., Islam, M.N., McCartney, D. and Kumar, A. (2019a), "Enhanced biomethane recovery from fat, oil, and grease through co-digestion with food waste and addition of conductive materials", Chemosphere, Vol. 236, p. 124362.

Chowdhury, P., Lau, K.H. and Pittayachawan, S. (2019b), "Operational supply risk mitigation of SME and its impact on operational performance", International Journal of Operations \& Production Management.

Dev, S.M. (2012), "Small farmers in India: challenges and opportunities", Indira Gandhi Institute of Development Research, pp. 8-14.

Diabat, A. (2014), "Hybrid algorithm for a vendor managed inventory system in a two-echelon supply chain”, European Journal of Operational Research, Vol. 238 No. 1, pp. 114-121.

Dwivedi, A. and Madaan, J. (2020), "A hybrid approach for modeling the key performance indicators of information facilitated product recovery system", Journal of Modelling in Management.

Dwivedi, A., Agrawal, D. and Madaan, J. (2019), "Sustainable manufacturing evaluation model focusing leather industries in India", Journal of Science and Technology Policy Management.

Dwivedi, A., Agrawal, D. and Madaan, J. (2020), "Identification and prioritization of issues to implementation of information-facilitated product recovery system for a circular economy", Modern Supply Chain Research and Applications.

Esteso, A., Alemany, M.M. and Ortiz, A. (2018), "Conceptual framework for designing agri-food supply chains under uncertainty by mathematical programming models", International Journal of Production Research, Vol. 56 No. 13, pp. 4418-4446.

Galal, N.M. and El-Kilany, K.S. (2016), "Sustainable agri-food supply chain with uncertain demand and lead time", International Journal of Simulation Modelling, Vol. 15 No. 3, pp. 485-496.

Gouda, S., Kerry, R.G., Das, G., Paramithiotis, S., Shin, H.S. and Patra, J.K. (2018), "Revitalization of plant growth promoting rhizobacteria for sustainable development in agriculture", Microbiological Research, Vol. 206, pp. 131-140.

Hu, J.Y., Zhang, J., Mei, M., min Yang, W. and Shen, Q. (2019), "Quality control of a four-echelon agri-food supply chain with multiple strategies", Information Processing in Agriculture. doi: 10.1016/j.inpa.2019.05.002.

Ingrao, C., Rana, R., Tricase, C. and Lombardi, M. (2015), "Application of carbon footprint to an agrobiogas supply chain in Southern Italy", Applied Energy, Vol. 149, pp. 75-88.

Intergovernmental panel on climate change (IPCC) (2014), available at: https://www.ipcc.ch/site/assets/ uploads/2018/03/WGIIIAR5_SPM_TS_Volume-3.pdf.

Jonkman, J., Barbosa-Póvoa, A.P. and Bloemhof, J.M. (2019), "Integrating harvesting decisions in the design of agro-food supply chains", European Journal of Operational Research, Vol. 276, pp. 247-258, doi: 10.1016/j.ejor.2018.12.024.

Kamble, S.S., Gunasekaran, A. and Sharma, R. (2020), "Modeling the blockchain enabled traceability in agriculture supply chain", International Journal of Information Management, Vol. 52, p. 101967.

Karuppiah, K., Sankaranarayanan, B., Ali, S.M., Chowdhury, P. and Paul, S.K. (2020), "An integrated approach to modeling the barriers in implementing green manufacturing practices in SMEs", Journal of Cleaner Production, p. 121737.

Kumar, R., Jha, A., Damodaran, A., Bangwal, D. and Dwivedi, A. (2020), "Addressing the challenges to electric vehicle adoption via sharing economy: an Indian perspective", Management of Environmental Quality: An International Journal.

Lash, J. and Wellington, F. (2007), Competitive Advantage on a Warming Planet. 
Mangla, S.K., Luthra, S., Rich, N., Kumar, D., Rana, N.P. and Dwivedi, Y.K. (2018), "Enablers to implement sustainable initiatives in agri-food supply chains", International Journal of Production Economics, Vol. 203, pp. 379-393, doi: 10.1016/j.ijpe.2018.07.012.

Meena, S.R., Meena, S.D., Pratap, S., Patidar, R. and Daultani, Y. (2019), "Strategic analysis of the Indian agri-food supply chain”, Opsearch, Vol. 56 No. 3, pp. 965-982, doi: 10.1007/s12597-019-00380-5.

Miranda-Ackerman, M.A., Azzaro-Pantel, C. and Aguilar-Lasserre, A.A. (2017), "A green supply chain network design framework for the processed food industry: application to the orange juice agrofood cluster", Computers and Industrial Engineering, Vol. 109, pp. 369-389, doi: 10.1016/j.cie.2017.04.031.

Mogale, D.G., Ghadge, A., Kumar, S.K. and Tiwari, M.K. (2019), "Modelling supply chain network for procurement of food grains in India", International Journal of Production Research, pp. 1-20.

Moktadir, M.A., Dwivedi, A., Ali, S.M., Paul, S.K., Kabir, G. and Madaan, J. (2019), "Antecedents for greening the workforce: implications for green human resource management", International Journal of Manpower.

Moktadir, M.A., Dwivedi, A., Rahman, A., Chiappetta Jabbour, C.J., Paul, S.K., Sultana, R. and Madaan, J. (2020), "An investigation of key performance indicators for operational excellence towards sustainability in the leather products industry", Business Strategy and the Environment.

Moreno-Camacho, C.A., Montoya-Torres, J.R., Jaegler, A. and Gondran, N. (2019), "Sustainability metrics for real case applications of the supply chain network design problem: a systematic literature review", Journal of Cleaner Production.

Niu, Q., Zhou, F. and Zhou, T. (2010), "Quantum genetic algorithm for hybrid flowshop scheduling problem to minimize total completion time”, LNCS, Vol. 6329, Part (II), pp. 21-29.

Orjuela-Castro, J.A., Sanabria-Coronado, L.A. and Peralta-Lozano, A.M. (2017), "Coupling facility location models in the supply chain of perishable fruits", Research in Transportation Business and Management, Vol. 24 November 2016, pp. 73-80, doi: 10.1016/j.rtbm.2017.08.002.

Paris Agreement on Climate (2016), available at: https://unfccc.int/news/india-deposits-instrument-ofratification-of-paris-agreement.

Prajapati, D., Zhou, F., Cheikhrouhou, N. and Pratap, S. (2019), "Minimizes the time window for delivery of orders in B2B E-commerce", Proceedings of the 5th International Conference on Industrial Engineering (ICIE 2019) (No. Conference), 12-14 December 2019.

Prajapati, D., Harish, A.R., Daultani, Y., Singh, H. and Pratap, S. (2020), "A clustering based routing heuristic for last-mile logistics in fresh food E-commerce", Global Business Review. doi: 10.1177/0972150919889797.

Prakash, G. (2018), "Managing welfare driven supply chains: insights from the Indian PDS", International Journal of Intelligent Enterprise, Vol. 5 Nos 1-2, pp. 70-96.

Prakash, S. and Vidyarthi, D.P. (2013), "A novel scheduling model for computational grid using quantum genetic algorithm”, Journal of Supercomputing Springer, Vol. 65 No. 2, pp. 742-770.

Pratap, S., Kumar, M., Cheikhrouhou, N. and Tiwari, M.K. (2015), "The robust quay crane allocation for a discrete bulk material handling port", 2015 IEEE International Conference on Industrial Engineering and Engineering Management (IEEM), IEEE, pp. 1174-1178.

Pratap, S., Zhang, M., Shen, C.L. and Huang, G.Q. (2019), "A multi-objective approach to analyse the effect of fuel consumption on ship routing and scheduling problem", International Journal of Shipping and Transport Logistics, Vol. 11 Nos 2-3, pp. 161-175.

Sazvar, Z., Rahmani, M. and Govindan, K. (2018), "A sustainable supply chain for organic, conventional agro-food products: the role of demand substitution, climate change and public health”, Journal of Cleaner Production, Vol. 194, pp. 564-583, doi: 10.1016/j.jclepro.2018.04.118.

Shardeo, V., Dwivedi, A. and Madaan, J. (2020a), "A study of decision and information synergy (DIS) focused inter-modal freight transportation (IFT) in the Indian context", Proceedings of the International Conference on Industrial Engineering and Operations Management, March 10-12, Dubai, pp. 772-779.

Shardeo, V., Patil, A. and Madaan, J. (2020b), "Critical success factors for blockchain technology adoption in freight transportation using Fuzzy ANP-modified TISM approach", International Journal of Information Technology and Decision Making. 
MSCRA

2,3

176

Sundarakani, B., De Souza, R., Goh, M. and Shun, C., (2008), "Measuring carbon footprints across the supply chain”, Proceedings of the 13th International Symposium on Logistics, July 2008, Bangkok, pp. 555-562.

Sundarakani, B., De Souza, R., Goh, M., Wagner, S.M. and Manikandan, S. (2010), "Modeling carbon footprints across the supply chain", International Journal of Production Economics, Vol. 128 No. 1, pp. 43-50.

Utomo, D.S., Onggo, B.S. and Eldridge, S. (2018), "Applications of agent-based modelling and simulation in the agri-food supply chains”, European Journal of Operational Research, Vol. 269 No. 3, pp. 794-805.

Wakeland, W., Cholette, S. and Venkat, K. (2012), "Food transportation issues and reducing carbon footprint", Green Technologies in Food Production and Processing, Springer, Boston, MA, pp. 211-236.

Wittneben, B. and Liyar, D. (2009), "Climate change basics for managers", Management Decision, Vol. 47, p. 1122, e1132.

Xiao, J., Yan, Y., Zhang, J. and Tang, Y. (2010), "A quantum inspired genetic algorithm for k- mean clustering”, Expert Systems with Applications, Vol. 37 No. 7, pp. 4966-4973.

\section{Further reading}

Bappy, M.M., Ali, S.M., Kabir, G. and Paul, S.K. (2019), "Supply chain sustainability assessment with Dempster-Shafer evidence theory: implications in cleaner production”, Journal of Cleaner Production, Vol. 237, p. 117771.

Cholette, S. and Venkat, K. (2009), "The energy and carbon intensity of wine distribution: a study of logistical options for delivering wine to consumers", Journal of Cleaner Production, Vol. 17 No. 16, pp. 1401-1413, Dalwai Committee Report on doubling farmers' income, available at: http:/agricoop.nic.in/doubling-farmers.

Dania, W.A.P., Xing, K. and Amer, Y. (2018), "Collaboration behavioural factors for sustainable agrifood supply chains: a systematic review", Journal of Cleaner Production, Vol. 186, pp. 851-864, doi: 10.1016/j.jclepro.2018.03.148.

FICCI-KPMG Report (2017), available at: http://ficci.in/state-study-page.asp?spid=20344\&stateid=1008http:// ficcifood360.in/download.php?f=KNOWLEDGE_PAPER_KPMG.pdf.

Mota, B., Gomes, M.I., Carvalho, M. and Barbosa-Povoa, A.P. (2018), "Sustainable supply chains: an integrated modeling approach under uncertainty”, Omega, Vol. 77, pp. 32-57.

Patidar, R., Agrawal, S. and Pratap, S. (2018), "Development of novel strategies for designing sustainable Indian agri-fresh food supply chain”, Sädhanā, Vol. 43 No. 10, p. 167.

Rueda, X., Garrett, R.D. and Lambin, E.F. (2017), "Corporate investments in supply chain sustainability: selecting instruments in the agri-food industry", Journal of Cleaner Production, Vol. 142, pp. 2480-2492, doi: 10.1016/j.jclepro.2016.11.026.

WHO (2016), available at: https:/www.who.int/sustainable-development/transport/health-risks/ climate-impacts/en/. 
Appendix 1

Agro-food supply chains

At $t=0$, Initialize Population

$P(t) Q=P\{() 1 p t,() 1 p t \ldots,() N p t\}$

Decode $P(t) Q$ in accordance with the problem

Calculate the fitness values of each individual solution in decoded population $\mathrm{PQ}(t)$

Observe the best solution and store it

If the stopping criteria is satisfied, then go to step 9

At $t=t+1$ update $\mathrm{PQ}(t)$ to $\mathrm{PQ}(t+1)$ by applying the quantum rotation

Again, decode $\mathrm{PQ}(t+1)$ in accordance with the problem

Calculate the fitness value of each individual; solution in decoded population $\mathrm{PQ}(t)$

Observe the best solution and store it

Execute mutation operator

If satisfied, then solution obtained

If the stopping criterion is not satisfied, go to step 5

Table A1.

Pseudo-code of quantum-based genetic algorithm

\section{Corresponding author}

Ajay Jha can be contacted at: ajha@ddn.upes.ac.in

For instructions on how to order reprints of this article, please visit our website:

www.emeraldgrouppublishing.com/licensing/reprints.htm

Or contact us for further details: permissions@emeraldinsight.com 